\title{
Applying the thresholds for clinical importance for fourteen key domains of the EORTC QLQ-C30: a latent class analysis of cancer survivors
}

\author{
Laura Keaver $^{1}$ (1) $\cdot$ Christopher McLaughlin $^{2}$
}

Received: 13 January 2021 / Accepted: 11 May 2021 / Published online: 25 June 2021

(c) The Author(s), under exclusive licence to Springer-Verlag GmbH Germany, part of Springer Nature 2021

\begin{abstract}
A person's quality of life is impacted from the beginning of their oncology experience. One of the most common tools to measure quality of life is the EORTC QLQ-C30. The absolute scores it produces can be difficult to interpret in the clinical setting, and thresholds to help identify those who require intervention have recently been introduced. The aim of this research was to identify heterogeneity of these thresholds for clinical importance using latent class analysis in cancer survivors (those undergoing and those who have completed treatment) attending a hospital in the northwest of Ireland. We identified 3 distinct classes of cancer survivors, using Mplus 6.11: high clinical impact (13.9\%), compromised physical function (40.3\%) and low clinical impact (45.9\%). The compromised physical function group were slightly more likely to be older $(\mathrm{OR}=1.042, \mathrm{p}<.05$, $\mathrm{CI}=1.000-1.086)$, not employed $(\mathrm{OR}=8.347, \mathrm{p}<.01, \mathrm{CI}=2.092-33.305)$, have lower PG-SGA scores $(\mathrm{OR}=.826, \mathrm{p}<.001$, $\mathrm{CI}=.755-.904)$, and not have been diagnosed in the last 2 years $(\mathrm{OR}=.325, \mathrm{p}<.05, \mathrm{CI}=.114-.923)$ compared to the high clinical impact group. The low clinical impact group were more likely to be female $(\mathrm{OR}=3.288, \mathrm{p}<.05, \mathrm{CI}=1.281-1.073)$, not employed $(\mathrm{OR}=10.129, \mathrm{p}<.01, \mathrm{CI}=2.572-39.882)$, have a lower $\mathrm{BMI}(\mathrm{OR}=.921, \mathrm{p}<.05, \mathrm{CI}=.853-.994)$, and lower PG-SGA scores $(\mathrm{OR}=.656, \mathrm{p}<.001, \mathrm{CI}=.573-.750)$ than the high clinical impact group. Functional and symptom issues impact on quality of life, and therefore, identifying those of clinical importance is crucial for developing supportive care strategies.
\end{abstract}

Keywords Clinical importance $\cdot$ Quality of life $\cdot$ Symptom burden $\cdot$ Functioning $\cdot$ Thresholds

\section{Introduction}

A person's quality of life is impacted from the beginning of their oncology experience [1], and those with cancer often report strong impairments in quality of life (QoL) compared to healthy populations $[2,3]$. Side effects of treatment such as anxiety, depressed mood, pain, fatigue, dyspnea, and appetite loss can impair activities of daily living in those with cancer, impacting on QoL [4, 5]. Cancer-related fatigue, experienced as emotional, physical, or cognitive exhaustion, is one of the most commonly reported side effects of cancer

Laura Keaver

Keaver.laura@itsligo.ie

1 Department of Health and Nutritional Science, Institute of Technology Sligo, Ash Lane, Sligo F91 YW50, Ireland

2 Department of Global Bus. \& Enterprise, Ulster Business School, Magee Campus, Londonderry BT48 7JL, Ireland and treatment [6-8] and can significantly impair multiple domains of QoL including physical functioning, cognitive functioning, and emotional functioning [6, 8, 9]. Correlations with survival rates have been reported for several $\mathrm{QoL}$ domains [10-12], and therefore, it has received much focus as a variable of importance.

One of the best ways to determine impacts of cancer on QoL is to ask patients themselves, and there are a number of tools available to measure QoL in this way. One of the more commonly used is the European Organization for Research and Treatment of Cancer Quality of Life Questionnaire (EORTC QLQ-C30) [13, 14]. This questionnaire assesses not just global health status but also five different functioning domains, eight symptom domains, and financial impact. While it was often used as an outcome measure for trials, it is more increasingly being used in clinical practice [15], where it appears to improve clinician-patient communication [16]. The absolute scores it produces, however, can be difficult to interpret in this setting and do not clearly indicate 
which functioning or symptom subscales require attention [17].

To better interpret the scores that this questionnaire generates, researchers have investigated cut-offs and thresholds for each of these scales to try to aid clinicians in easily identifying clinically important impairment of function or symptom burden. These have varied significantly over the years and all come with their own inherent limitations, such as using the same threshold for each of the domains [18] or use of percentiles with a general population reference point [19]. Giesinger et al. have recently developed thresholds for clinical importance based on mixed-methods work with patients and healthcare professionals to determine what makes a symptom or burden clinically important [20].

In clinical practice, these thresholds will help the clinician to be able to identify symptom and functional health problems that require attention. The aim of this research was to apply these thresholds to a cohort of Irish Cancer Survivors (both undergoing and completed treatment) and to examine heterogeneity of these thresholds for clinical importance using latent class analysis. A secondary aim was to determine whether these groups differed by select demographic and health characteristics.

\section{Method}

\section{Sample}

Participants were recruited through the oncology day ward and outpatient department in Sligo University Hospital between September 2019 and March 2020. Ethical approval was granted by the Research Ethics Committee at Sligo University Hospital.

\section{Measures}

Individuals completed a demographic questionnaire (age, gender, cancer duration, education, employment, treatment status), the EORTC QLQ-C30 [13], the Patient Generated Subjective Global Assessment Short Form (PG-SGA SF) [21] questionnaire, and a handgrip strength test using a handgrip dynamometer (dominant hand, result measured in $\mathrm{kg}$ ). Weight and height were measured by an oncology nurse, and body mass index (BMI) was calculated using the formula weight/height ${ }^{2}$.

The PG-SGA SF is a screening tool for malnutrition risk which is considered the reference method to assess malnutrition in an oncology setting [22]; it is not, however, an oncology-specific tool. It consists of four sections to be completed by the patient which address weight history (patient is asked to indicate current weight and height, weight 1 month ago, weight 6 months ago, and also to answer the following: during the past 2 weeks my weight has increased, decreased, stayed the same), food intake (compared to my normal intake, I would rate my food intake during the past month as unchanged, more than usual, less than usual; individuals are then asked what type of food, e.g. normal food, liquids, nutritional supplements), nutrition impact symptoms (e.g. have kept me from eating enough in the last 2 weeks, check all that apply-list of 14 impact symptoms and option to choose and specific 'other'), and activities/function (rate activity over the last month from normal to severe limitations/bed bound). These were scored using standardised guidelines with a minimum of 0 and a maximum of 36 points being achievable [21]. A higher score reflects a greater risk of malnutrition.

The EORTC QLQ-C30 is a validated measure for determining quality of life in cancer patients. This provides scoring (0-100) for five functioning scales (physical, role, emotional, cognitive, and social), eight symptom scales (fatigue, nausea and vomiting, pain, dyspnoea, insomnia, appetite loss, constipation, and diarrhoea), and perceived financial impact. Example questions include, 'in the past week have you have difficulty remembering things'; 'did you feel depressed'; 'have you had trouble sleeping'; 'were you limited in doing either your work or other daily activities?' For the current study, the five items of the functioning subscales had favourable factor loads [23] and yielded a favourable level [24] of internal consistency ( $\alpha=0.77)$. Likewise, for the symptom and financial subscales, all nine items had favourable factor loads [23] and yielded a favourable level [24] of internal consistency $(\alpha=0.70)$.

The thresholds for clinical importance (TCIs) for each of the quality of life subscales were determined using the validated measures developed by Giesinger et al. [20]. Individuals were then binary categorised as meeting or not meeting this threshold. The TCIs for the five functioning scales were physical functioning (83); role functioning (58); social functioning (58); emotional functioning (71), and cognitive functioning (75). While the TCIs for the symptom scales were fatigue (39); pain (25); nausea/vomiting (8); sleep disturbance (50); dyspnoea (17); appetite loss (50); constipation (50); diarrhoea (17), and financial impact (17).

\section{Materials}

\section{Proposed analytical approach}

We employed latent class analysis (LCA) as the main statistical approach to investigate the number of possible latent typologies within the TCI data. Using the binary-observed TCI indicators, it was expected that LCA would identify possible typologies $[25,26]$ as it is seen as a 'person-centred' statistical process [26]. Each of the conditional latent class 
models to be tested utilised all fourteen binary indicators (TCI). All models were estimated using Mplus 6.11 [27] along with a robust maximum likelihood [28]. Also, in order to avoid solutions based on local maxima, 100 random sets of start value were used alongside 20 final stage optimisations. Model fit was assessed using several information theory-based fit statistics; Akaike information criterion (AIC) [29], Bayesian information criterion (BIC) [30], and the sample-sized-adjusted BIC (ssaBIC) [31]. The model that produces the lowest values on each of these is the best fitting model. Additionally, the Lo-Mendell-Rubin-adjusted likelihood ratio test (LRT) [32] has also been employed to assist in class enumeration, where a non-significant value suggests a class lower should be considered. Nylund et al. [33] have identified the benefits of the LRT [32] over the BIC in aiding decision-making over the number of classes to accept.

\section{Multinominal logistic regression}

Two multinominal logistic regressions were carried out to explore the relationship between (i) key demographic variables (age, education (primary/non-completed secondary; completed secondary/training; third level (BA, BSc, Diploma); postgraduate degree/higher), gender, and employment (this binary variable allowed participants to be classified as $(1=$ no $)$ not working (retired/unemployed $)$ and $(0=$ yes) working (full-time, part-time, or self-employed) at present) (model 1) and (ii) health-related factors (BMI $\left(\mathrm{kg} / \mathrm{m}^{2}\right)$, handgrip (kg), PG-SGA score, diagnosis duration $(\leq 2$ years or $>2$ years), and treatment status (currently receiving treatment or completed treatment)) (model 2) with participant classifications.

\section{Results}

\section{Characteristics}

Two hundred thirty-two participants were recruited. The cohort had a mean age of $63.5( \pm 11.9)$ years. The majority were female $(\mathrm{n}=138,61.1 \%)$, diagnosed less than 5 years $(\mathrm{n}=167,73.9 \%)$ and almost half $(\mathrm{n}=112,48.5 \%)$ were retired. The majority were currently receiving treatment $(n=159,70.4 \%)$. The main treatment type being received was chemotherapy $(n=129,81.1 \%$ of those receiving treatment), followed by hormonal therapy $(n=19,11.9 \%$ of those receiving treatment). The most common diagnosis was breast cancer $(n=58,25.7 \%)$, followed by colorectal $(n=32$, $13.8 \%)$, haematological $(n=28,21.1 \%)$, lung $(n=12,5.2 \%)$, and upper gastrointestinal/liver $(n=10,4.3 \%)$. Gynaecological, urinary, head and neck, skin, and bone cancers made up the remaining cases.

\section{Descriptive trends of indicators}

Table 1 presents the descriptive breakdown for each of the TCI indicators to be included within the LCA model. A total of fourteen indicators were employed and each was measured on a no (0) or yes (1) binary response set. Descriptive analysis indicated that the issue that met the threshold for clinical importance most often was dyspnoea (40.9\%) while the least experienced were appetite loss (12.6\%) and constipation $(12.6 \%)$.

\section{Fit indices and latent class analyses}

To explore the number of TCI typologies, analysis started firstly with a one class model and continued until models failed to add significantly to the previous model. In other terms, once the conditional model failed to add statistically to its predecessor, the analysis would cease. Each of the TCI model fit indices is displayed in Table 2. A three-class model was selected as the AIC was lower in the three-class solution (AIC $=3392.618)$ than the two-class solution $(\mathrm{AIC}=3443.829)$. The BIC was reported to be more favourable for the three-class model $(\mathrm{BIC}=3544.084)$ than the four-class model $(\mathrm{BIC}=3575.481)$. Additionally, since the four-class model added nothing significantly ( $L R T=50.240$, $\mathrm{p}=0.191)$ to the three-class model, the three-class model was preferred. Lastly, a three-class provides a more parsimonious explanation than a four-class.

Table 3 contains the posterior probabilities for each of the three-classes along with associated descriptive information.

Table 1 Proportion of individuals that meet the threshold for clinical importance for each of the QOL subscales

\begin{tabular}{llllll}
\hline Indicators of clinical importance & \multicolumn{2}{l}{ No } & & \multicolumn{2}{l}{ Yes } \\
\cline { 2 - 3 } \cline { 6 - 7 } & $\mathrm{n}$ & $\%$ & & $\mathrm{n}$ & $\%$ \\
\hline Physical functioning & 131 & $57 \%$ & & 99 & $43 \%$ \\
Role functioning & 176 & $76.2 \%$ & & 55 & $23.8 \%$ \\
Emotional functioning & 162 & $71.4 \%$ & & 65 & $28.6 \%$ \\
Cognitive functioning & 157 & $68 \%$ & & 74 & $32 \%$ \\
Social functioning & 170 & $73.9 \%$ & 60 & $26.1 \%$ \\
Fatigue & 148 & $64.3 \%$ & 82 & $35.7 \%$ \\
Nausea & 171 & $74 \%$ & & 60 & $26 \%$ \\
Pain & 166 & $71.9 \%$ & 65 & $28.1 \%$ \\
Dyspnoea & 136 & $59.1 \%$ & & 94 & $40.9 \%$ \\
Sleep disturbances & 156 & $67.8 \%$ & & 74 & $32.2 \%$ \\
Appetite loss & 202 & $87.4 \%$ & & 29 & $12.6 \%$ \\
Constipation & 202 & $87.4 \%$ & & 29 & $12.6 \%$ \\
Diarrhoea & 178 & $77.1 \%$ & & 53 & $22.9 \%$ \\
Financial & 145 & $63.3 \%$ & & 84 & $36.7 \%$ \\
\hline
\end{tabular}

Note: 'yes' indicates individuals meeting the threshold for clinical importance for this quality of life measure. 
Table 2 Latent class fit indices for two to four class solutions

\begin{tabular}{lllllll}
\hline Classes & LL & Par & AIC & BIC & LRT & $p$ \\
\hline 1 & -1865.728 & 14 & 3759.456 & 3807.649 & - & - \\
2 & -1692.914 & 29 & 3443.829 & 3543.659 & 345.627 & 0.000 \\
3 & $-\mathbf{1 6 5 2 . 3 0 9}$ & $\mathbf{4 4}$ & $\mathbf{3 3 9 2 . 6 1 8}$ & $\mathbf{3 5 4 4 . 0 8 4}$ & $\mathbf{8 1 . 2 1 1}$ & $\mathbf{0 . 0 3 9}$ \\
4 & -1627.189 & 59 & 3372.378 & 3575.481 & 50.240 & 0.191 \\
\hline
\end{tabular}

Note: $A I C$, Akaike information criterion; BIC, Bayesian information criterion; $L R T$, Lo-Mendell-Rubin likelihood ratio test. Best fitting LCA model in bold.
Table 3 Descriptive information regarding the three classes that arose from LCA*

\begin{tabular}{llll}
\hline Indicators & $\begin{array}{l}\text { High clinical } \\
\text { impact } \\
\text { (Class 1) }\end{array}$ & $\begin{array}{l}\text { Low clinical } \\
\text { impact } \\
\text { (Class 2) }\end{array}$ & $\begin{array}{l}\text { Compromised } \\
\text { physical func- } \\
\text { tion (Class 3) }\end{array}$ \\
\hline Physical functioning & $\mathbf{0 . 8 5}$ & 0.08 & $\mathbf{0 . 6 5}$ \\
Role functioning & $\mathbf{0 . 6 5}$ & 0.04 & 0.30 \\
Emotional functioning & $\mathbf{0 . 7 8}$ & 0.07 & 0.34 \\
Cognitive functioning & $\mathbf{0 . 6 9}$ & 0.12 & 0.40 \\
Social functioning & $\mathbf{0 . 8 2}$ & 0.05 & 0.29 \\
Fatigue & $\mathbf{0 . 9 3}$ & 0.00 & $\mathbf{0 . 5 2}$ \\
Nausea & $\mathbf{0 . 8 2}$ & 0.11 & 0.22 \\
Pain & $\mathbf{0 . 8 7}$ & 0.08 & 0.29 \\
Dyspnoea & $\mathbf{0 . 6 3}$ & 0.22 & $\mathbf{0 . 5 2}$ \\
Sleep disturbances & $\mathbf{0 . 8 0}$ & 0.20 & 0.28 \\
Appetite loss & 0.46 & 0.01 & 0.13 \\
Constipation & 0.29 & 0.04 & 0.15 \\
Diarrhoea & $\mathbf{0 . 5 7}$ & 0.19 & 0.15 \\
Financial & $\mathbf{0 . 6 4}$ & 0.32 & 0.33 \\
Percentage & 13.9 & 45.9 & 40.3 \\
n & 32 & 106 & 93 \\
\hline
\end{tabular}

Note: Higher probabilities $(>0.50)$ for meeting the threshold of clinical importance for each of the QoL domains are bolded.

*Two hundred thirty-one were successfully classified by LCA.
Regarding class size, it is clear from the table that the largest group is the second class $(\mathrm{n}=106,45.9 \%)$ and this group is characterised by very low probability of experiencing any of the TCI indicators. Posterior probabilities ranged from 0.01 to 0.23 . Thus, this class of participants was labelled 'low clinical impact' based on their probability of low clinical importance. The next largest in participant size was the third group $(\mathrm{n}=93,40.3 \%)$, and interestingly, this class was characterised by three TCI indictors of higher clinical importance. More specifically, higher posterior probabilities were reported for physical functioning $(0.65)$, fatigue $(0.52)$, and dyspnoea (0.52), thus identifying this group as 'compromised physical function'. Lastly, the smallest class $(n=32$, $13.9 \%$ ) was characterised by reporting higher posterior probability scores than the other two groups. All indictors had a posterior probability score higher than 0.50 except for two indicators, namely appetite loss (0.46) and constipation (0.29). Examining the reported probabilities, this group was labelled 'high clinical impact'. A graph was also developed to aid the interpretation of the probabilities and how the three classes distinguish from each other across each of the symptom indicators (Fig. 1).

\section{Multinominal logistic regression}

In model 1 , age had only a significant effect within class 3 (compromised physical functioning) $(\mathrm{OR}=1.042$,
Fig. 1 Probability of clinical importance for each of the latent classes for the 14 domains of the EORTC QLQ-C30

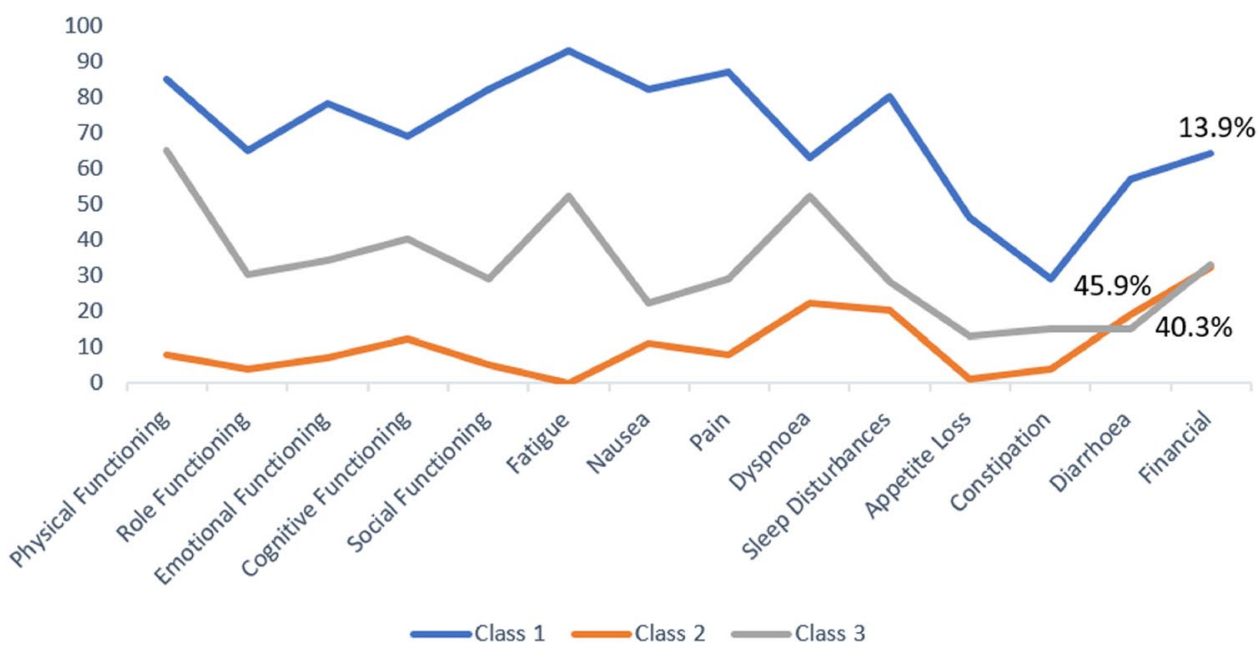


$\mathrm{p}<0.05, \mathrm{CI}=1.000-1.086)$ but not class 2 (low clinical impact) in comparison to the reference group (high clinical impact). Individuals in this group were slightly more likely to be older than the reference class. There was no significant effect by age for education across any of the classes. Gender was only reported significant in class 2 (low clinical impact) $(\mathrm{OR}=3.288, \mathrm{p}<0.05$, $\mathrm{CI}=1.281-1.073$ ). Here individuals were over 3 times more likely to be female in this group in comparison to class 1 (high clinical impact). Employment status was reported to have a significant effect on both classes (class $2: \mathrm{OR}=10.129, \mathrm{p}<0.01, \mathrm{CI}=2.572-39.882$; class 3 : $\mathrm{OR}=8.347, \mathrm{p}<0.01, \mathrm{CI}=2.092-33.305)$ in comparison to the reference class; more specifically, non-workers were over 10 times more likely to be in class 2 (low clinical impact) than the referent class (high clinical impact), while class 3 individuals (compromised physical functioning) were over 8 times more likely to be not-working in comparison to the referent class (Table 4).

Compared to class 1 (high clinical impact) within model 2, the odds of belonging to class 2 (low clinical impact) decreased significantly by having higher BMI $(\mathrm{OR}=0.921, \mathrm{p}<0.05, \mathrm{CI}=0.853-0.994)$ and PG$\mathrm{SGA}(\mathrm{OR}=0.656, \mathrm{p}<0.001, \mathrm{CI}=0.573-0.750)$ scores. Similarly, the odds of belonging to class 3 (compromised physical functioning) decreased significantly for those with higher PG-SGA $(\mathrm{OR}=0.826, \mathrm{p}<0.001$, $\mathrm{CI}=0.755-0.904)$, but also for those diagnosed within the past 2 years $(\mathrm{OR}=0.325, \mathrm{p}<0.05, \mathrm{CI}=0.114-0.923)$. All other associations were reported non-significant (Table 5).

\section{Discussion}

We identified 3 distinct classes of cancer survivors based on the thresholds for clinical importance for each of the 14 subscales of the EORTC QLQ-C30. Approximately $46 \%$ of the cohort were classified as having a very low probability of meeting the threshold for clinical importance for any of the QoL scales. The remaining participants were classified into one of two classes which demonstrated clinical importance for either the majority of QOL scales or those related to physical functioning, e.g. physical function, fatigue, and dyspnoea.

The distinct classes of low clinical impact, compromised physical function, and high clinical impact indicates that classifying quality of life by an average score may be limiting. In that case, the clinical implications of the various domains may not be evident. Almost $41 \%$ of the total cohort met the threshold for clinical importance for dyspnoea, $43 \%$ for physical functioning, and $36 \%$ for fatigue, none of which will be evident by looking at the overall Global Health Status score.

Those in the compromised physical function group represented $40 \%$ of the total cohort and are likely to experience clinically important impairments in physical function, fatigue, and dyspnoea. Fatigue is one of the most common and impactful symptoms experienced by those with cancer and is associated with profound psychological distress [6, 34]. It has been rated as one of the more troublesome symptoms and impacts more negatively on activities of daily living than any other cancer-related symptom $[9,35]$. Physical function has been related to fatigue [36], is a frequent consequence of cancer and its treatments, and impacts on quality of life and contributes to disease burden and psychosocial
Table 4 Odds ratios and confidence intervals (95\%) for demographic factors (model 1 )

\begin{tabular}{|c|c|c|c|c|c|c|}
\hline \multicolumn{2}{|c|}{$\begin{array}{l}\text { Reference group: Class } 1 \text { (High } \\
\text { clinical impact) }\end{array}$} & \multirow[t]{2}{*}{ B } & \multirow[t]{2}{*}{ SE } & \multirow[t]{2}{*}{ OR } & \multicolumn{2}{|c|}{$\begin{array}{l}95 \% \text { confidence } \\
\text { interval }\end{array}$} \\
\hline & & & & & Lower & Upper \\
\hline \multirow{4}{*}{$\begin{array}{l}\text { Class } 2 \text { (Low } \\
\text { clinical } \\
\text { impact) }\end{array}$} & Age & 0.030 & 0.021 & 1.030 & $0.989 /$ & 1.073 \\
\hline & Education & 0.353 & 0.289 & 1.423 & $0.808 /$ & 2.506 \\
\hline & $\begin{array}{l}\text { Gender } \\
(\mathrm{M}=0, \mathrm{~F}=1)\end{array}$ & 1.190 & 0.481 & $3.288^{*}$ & $1.281 /$ & 8.441 \\
\hline & $\begin{array}{l}\text { Employment } \\
(\mathrm{Y}=0, \mathrm{~N}=1)\end{array}$ & 2.315 & 0.699 & $10.129 * *$ & $2.572 /$ & 39.882 \\
\hline \multirow{4}{*}{$\begin{array}{l}\text { Class } 3 \\
\text { (Com- } \\
\text { promised } \\
\text { physical } \\
\text { functioning) }\end{array}$} & Age & 0.041 & 0.021 & $1.042 *$ & $1.000 /$ & 1.086 \\
\hline & Education & -0.059 & 0.291 & 0.942 & $0.533 /$ & 1.666 \\
\hline & $\begin{array}{l}\text { Gender } \\
(\mathrm{M}=0, \mathrm{~F}=1)\end{array}$ & 0.221 & 0.487 & 1.248 & $0.481 /$ & 3.238 \\
\hline & $\begin{array}{l}\text { Employment } \\
(\mathrm{Y}=0, \mathrm{~N}=1)\end{array}$ & 2.122 & 0.706 & $8.347 * *$ & $2.092 \backslash$ & 33.305 \\
\hline
\end{tabular}

Note: $B$ estimate, $S E$ standard error, $O R$ odds ratio, $*=\mathrm{p}<0.05, * * \mathrm{p}<0.01, * * * \mathrm{p}<0.001$. 
Table 5 Odds ratios and confidence intervals $(95 \%)$ for health-related factors (model 2)

\begin{tabular}{|c|c|c|c|c|c|c|c|}
\hline \multicolumn{2}{|c|}{$\begin{array}{l}\text { Reference group: Class } 1 \text { (High clinical } \\
\text { impact) }\end{array}$} & \multirow[t]{2}{*}{$\mathrm{B}$} & \multirow[t]{2}{*}{ SE } & \multirow[t]{2}{*}{ OR } & & \multicolumn{2}{|c|}{$\begin{array}{l}95 \% \text { confidence } \\
\text { interval }\end{array}$} \\
\hline & & & & & & Lower & Upper \\
\hline \multirow{5}{*}{$\begin{array}{l}\text { Class } \\
2 \text { (Low } \\
\text { clinical } \\
\text { impact) }\end{array}$} & BMI $\left(\mathrm{kg} / \mathrm{m}^{2}\right)$ & -0.083 & 0.039 & 0.921 & $*$ & 0.853 & 0.994 \\
\hline & Handgrip (kg) & 0.044 & 0.030 & 1.045 & & 0.985 & 1.108 \\
\hline & PG-SGA & -0.422 & 0.069 & 0.656 & $* * *$ & 0.573 & 0.750 \\
\hline & $\begin{array}{l}\text { Diagnosed within past } 2 \text { years } \\
(\mathrm{N}=0, \mathrm{Y}=1)\end{array}$ & -0.914 & 0.575 & 0.401 & & 0.130 & 1.238 \\
\hline & $\begin{array}{l}\text { Receiving treatment } \\
(\mathrm{N}=0, \mathrm{Y}=1)\end{array}$ & -0.428 & 0.586 & 0.652 & & 0.207 & 2.055 \\
\hline \multirow{5}{*}{$\begin{array}{l}\text { Class } \\
3 \text { (Com- } \\
\text { pro- } \\
\text { mised } \\
\text { physical } \\
\text { func- } \\
\text { tioning) }\end{array}$} & $\mathrm{BMI}\left(\mathrm{kg} / \mathrm{m}^{2}\right)$ & -0.059 & 0.036 & 0.943 & & 0.878 & 1.012 \\
\hline & Handgrip (kg) & -0.006 & 0.029 & 0.994 & & 0.940 & 1.052 \\
\hline & PG-SGA & -0.191 & 0.046 & 0.826 & $* * *$ & 0.755 & 0.904 \\
\hline & $\begin{array}{l}\text { Diagnosed within past } 2 \text { years } \\
(\mathrm{N}=0, \mathrm{Y}=1)\end{array}$ & -1.124 & 0.533 & 0.325 & $*$ & 0.114 & 0.923 \\
\hline & $\begin{array}{l}\text { Receiving treatment } \\
(\mathrm{N}=0, \mathrm{Y}=1)\end{array}$ & -0.237 & 0.538 & 0.789 & & 0.275 & 2.265 \\
\hline
\end{tabular}

Note: $B$ estimate, $S E$ standard error, $O R$ odds ratio, $*=\mathrm{p}<0.05, * * \mathrm{p}<0.01, * * * \mathrm{p}<0.001$. distress [37]. Dyspnoea can impact on activities of daily living and in particular physical activities [4]. Increased physical activity has been associated with reduced cancer associated mortality [38] as well as a reduced symptom burden $[39,40]$. Exercise interventions have been shown to have beneficial effects on QoL, physical function, social function, and fatigue [41]. All three symptoms in this class will impact on an individual's ability to undertake physical activity or partake in exercise-based rehabilitation and therefore potentially prevent them from experiencing these benefits.

Fourteen percent of the cohort belonged to the high clinical impact group. Though the smallest group, they were the most important as they identified with higher clinical importance in most of the QoL indicators, except for appetite loss and constipation. They were more likely to have higher PG-SGA scores, meaning a higher risk of malnutrition than those in the compromised physical function group and the low clinical impact group. Nutritional status has been shown to be a significant predictor of $\mathrm{QoL}$ in those with cancer, and therefore, this finding is not surprising [42]. Cancer and its treatment can lead to changes in physiological and psychological domains, which in turn can negatively influence a patient's QoL through its impacts on nutritional status [43]. Nutrition support should therefore be included as part of all oncology care. The treatment of symptoms and impaired function will help improve overall quality of life.

Those in the high clinical impact group were more likely to be diagnosed in the last 2 years than those in the compromised physical function group. This indicates that while symptom burden may be higher in this cohort in the initial years after diagnosis, the symptoms associated with physical function impairment such as fatigue can persist much longer.
Previous work has indicated that up to $30 \%$ of cancer survivors can experience this symptom for several years after diagnosis [44]. Those in the higher symptom burden group were also more likely to be younger than those in the compromised physical function group. This is a topic of debate; some studies have shown similar findings where those who were younger experienced a higher symptom burden [45], while other studies have not agreed with this [46, 47]. Some potential reasons for younger individuals being more likely to be in the high clinical impact group could be that there is a higher likelihood of them receiving aggressive therapies [48], potentially a higher level of functioning, and therefore greater expectations for the resumption of pre-cancer abilities [49] or in some cases a higher prevalence of advanced cancers [50].

Interestingly, those in the low clinical impact group were more likely to be female than those in the high clinical impact group. Gender-based differences in symptom burdens experienced by those with cancer tend to be inconsistent across the literature $[45,51,52]$. The only socioeconomicbased difference that was observed in class membership was that those in the compromised physical function and low clinical impact group were more likely to not be working; however, a large proportion of our cohort was retired which may account for this finding. Those in the low clinical impact group were more likely to be older which would support this. In addition, those in the compromised function group were more likely to be female and this is a group that can be more likely to be homemakers or work part-time which could also explain this finding.

Importantly, this research through the identification of these distinct classes will allow clinicians to better identify 
those at need for intervention. This is the first study to implement the thresholds for clinical importance using LCA, and therefore, there are no previous studies to compare to, however, previous work which implemented LCA for the healthrelated QoL scores reported four distinct classes in lung cancer survivors, three of which are similar to those reported in this study: high health-related quality of life (HRQOL), low HRQOL, and mobility/usual activity impairment [53]. This study also reported $46 \%$ of the cohort in the high HRQOL class, identical to the $46 \%$ we report as being in the low clinical impact group.

There are limitations to our study. First, the current findings are specific to our cohort and analysis should be repeated to validate our findings. Second, for those who have completed treatment, the EORTC QLQ-C30 may not adequately reflect the physical and psychosocial problems experienced during this stage. Issues such as fear of recurrence or returning to work may become more common; however, the EORTC QLQ-C30 focusses more on acute and treatmentrelated symptoms. Finally, the data was collected into the early months of 2020, and therefore, some domains could have been impacted by the early stages of the COVID-19 pandemic.

\section{Conclusion}

This research identified three distinct classes of cancer survivors based on the thresholds of clinical importance for fourteen key domains of the EORTC QLQ-C30 questionnaire that will help clinicians to better identify those in need of intervention. Functional and symptom issues impact on quality of life and therefore identifying those of clinical importance is crucial for developing supportive care strategies.

Acknowledgements We would like to thank all those who took the time to take part in this study.

Author contribution LK conceived the idea, designed the study, contributed to data collection and analysis, and wrote the initial draft. $\mathrm{CM}$ guided and contributed to statistical analysis and contributed to the methodology section of the manuscript. All authors reviewed and approved the final manuscript.

Availability of data and material The datasets generated during and/or analysed during the current study are available from the corresponding author on reasonable request.

\section{Code availability N/A}

\section{Declarations}

Ethics approval Research and Ethics Foundation, Sligo University Hospital.
Consent to participate Written consent was obtained from all participants.

Consent for publication Participants provided written consent for the publication of this research.

Conflict of interest The authors declare no competing interests.

\section{References}

1. Peters E, Mendoza Schulz L, Reuss-Borst M (2016) Quality of life after cancer-How the extent of impairment is influenced by patient characteristics. BMC Cancer 16(1):787. https://doi.org/10. 1186/s12885-016-2822-z

2. Waldmann A, Pritzkuleit R, Raspe H, Katalinic A (2007) The OVIS study: health related quality of life measured by the EORTC QLQ-C30 and -BR23 in German female patients with breast cancer from Schleswig-Holstein. Qual Life Res 16(5):767-776. https://doi.org/10.1007/s11136-006-9161-5

3. Koch L, Jansen L, Herrmann A, Stegmaier C, Holleczek B, Singer S et al (2013) Quality of life in long-term breast cancer survivors-a 10-year longitudinal population-based study. Acta Oncol 52(6):1119-1128. https://doi.org/10.3109/0284186x.2013.774461

4. Tanaka K, Akechi T, Okuyama T, Nishiwaki Y, Uchitomi Y (2002) Impact of dyspnea, pain, and fatigue on daily life activities in ambulatory patients with advanced lung cancer. J Pain Symptom Manage 23(5):417-423. https://doi.org/10.1016/s08853924(02)00376-7

5. Deshields TL, Potter P, Olsen S, Liu J (2014) The persistence of symptom burden: symptom experience and quality of life of cancer patients across one year. Support Care Cancer 22(4):10891096. https://doi.org/10.1007/s00520-013-2049-3

6. Hofman M, Ryan JL, Figueroa-Moseley CD, Jean-Pierre P, Morrow GR (2007) Cancer-related fatigue: the scale of the problem. Oncologist 12(Suppl 1):4-10. https://doi.org/10.1634/theoncolog ist.12-S1-4

7. Cella D, Davis K, Breitbart W, Curt G (2001) Cancer-related fatigue: prevalence of proposed diagnostic criteria in a United States sample of cancer survivors. J Clin Oncol 19(14):33853391. https://doi.org/10.1200/jco.2001.19.14.3385

8. Borneman T, Piper BF, Koczywas M, Munevar CM, Sun V, Uman GC et al (2012) A qualitative analysis of cancer-related fatigue in ambulatory oncology. Clin J Oncol Nurs 16(1):E26-32. https:// doi.org/10.1188/12.Cjon.E26-e32

9. Curt GA, Breitbart W, Cella D, Groopman JE, Horning SJ, Itri LM et al (2000) Impact of cancer-related fatigue on the lives of patients: new findings from the Fatigue Coalition. Oncologist 5(5):353-360. https://doi.org/10.1634/theoncologist.5-5-353

10. Coates A, Thomson D, McLeod GR, Hersey P, Gill PG, Olver IN et al (1993) Prognostic value of quality of life scores in a trial of chemotherapy with or without interferon in patients with metastatic malignant melanoma. Eur J Cancer 29a(12):1731-1734. https://doi.org/10.1016/0959-8049(93)90115-V

11. Gotay CC, Kawamoto CT, Bottomley A, Efficace F (2008) The prognostic significance of patient-reported outcomes in cancer clinical trials. J Clin Oncol 26(8):1355-1363. https://doi.org/10. 1200/jco.2007.13.3439

12. Maisey NR, Norman A, Watson M, Allen MJ, Hill ME, Cunningham D (2002) Baseline quality of life predicts survival in patients with advanced colorectal cancer. Eur J Cancer 38(10):1351-1357. https://doi.org/10.1016/s0959-8049(02)00098-9

13. Aaronson NK, Ahmedzai S, Bergman B, Bullinger M, Cull A, Duez NJ et al (1993) The European Organization for Research 
and Treatment of Cancer QLQ-C30: a quality-of-life instrument for use in international clinical trials in oncology. J Natl Cancer Inst 85(5):365-376. https://doi.org/10.1093/jnci/85.5.365

14. Luckett T, King MT, Butow PN, Oguchi M, Rankin N, Price MA et al (2011) Choosing between the EORTC QLQ-C30 and FACT$\mathrm{G}$ for measuring health-related quality of life in cancer clinical research: issues, evidence and recommendations. Ann Oncol 22(10):2179-2190. https://doi.org/10.1093/annonc/mdq721

15. Basch E, Barbera L, Kerrigan CL, Velikova G (2018) Implementation of patient-reported outcomes in routine medical care. Amer Soc Clin Oncol Educ Book 38:122-134. https://doi.org/10.1200/ edbk_200383

16. Velikova G, Booth L, Smith AB, Brown PM, Lynch P, Brown JM et al (2004) Measuring quality of life in routine oncology practice improves communication and patient well-being: a randomized controlled trial. J Clin Oncol 22(4):714-724. https://doi.org/10. 1200/jco.2004.06.078

17. Wintner LM, Sztankay M, Aaronson N, Bottomley A, Giesinger JM, Groenvold M et al (2016) The use of EORTC measures in daily clinical practice-a synopsis of a newly developed manual. Eur J Cancer 68:73-81. https://doi.org/10.1016/j.ejca.2016.08.024

18. Klinkhammer-Schalke M, Koller M, Steinger B, Ehret C, Ernst B, Wyatt JC et al (2012) Direct improvement of quality of life using a tailored quality of life diagnosis and therapy pathway: randomised trial in 200 women with breast cancer. Br J Cancer 106(5):826-838. https://doi.org/10.1038/bjc.2012.4

19. Gulbrandsen N, Hjermstad MJ, Wisløff F (2004) Interpretation of quality of life scores in multiple myeloma by comparison with a reference population and assessment of the clinical importance of score differences. Eur J Haematol 72(3):172-180. https://doi. org/10.1046/j.0902-4441.2003.00195.x

20. Giesinger JM, Loth FLC, Aaronson NK, Arraras JI, Caocci G, Efficace $\mathrm{F}$ et al (2020) Thresholds for clinical importance were established to improve interpretation of the EORTC QLQ-C30 in clinical practice and research. J Clin Epidemiol 118:1-8. https:// doi.org/10.1016/j.jclinepi.2019.10.003

21. Pt-Global (2014) Patient Generated Subjective Global Assessment (PG-SGA). http://pt-global.org/?page_id=13. Accessed 05/08/2020

22. Jager-Wittenaar H, Ottery FD (2017) Assessing nutritional status in cancer: role of the Patient-Generated Subjective Global Assessment. Curr Opin Clin Nutr Metab Care 20(5):322-329. https://doi. org/10.1097/mco.0000000000000389

23. Field A (2009) Discovering statistics using SPSS, 3rd edn. Sage Publications Ltd., London

24. Kline P (2000) The handbook of psychological testing. Taylor and Francis, New York

25. Tein JY, Coxe S, Cham H (2013) Statistical power to detect the correct number of classes in latent profile analysis. Struct Equ Modeling 20(4):640-657. https://doi.org/10.1080/10705511.2013. 824781

26. Wang J, Wang X (2012) Structural equation modeling: applications using Mplus. Wiley, Chichester

27. Muthén LK, Muthén BO (2010) Mplus user's guide, Sixth edn. Muthén \& Muthén, Los Angeles

28. Yuan K-H, Bentler PM (2000) Three likelihood-based methods for mean and covariance structure analysis with nonnormal missing data. Sociol Methodol 30(1):165-200. https://doi.org/10.1111/ 0081-1750.00078

29. Akaike H (1987) Factor analysis and AIC. Psychometrika 52(3):317-332. https://doi.org/10.1007/BF02294359

30. Schwarz G (1978) Estimating the dimension of a model. Ann Stat 6(2):461-464

31. Sclove SL (1987) Application of model-selection criteria to some problems in multivariate analysis. Psychometrika 52(3):333-343. https://doi.org/10.1007/BF02294360
32. Lo Y, Mendell NR, Rubin DB (2001) Testing the number of components in a normal mixture. Biometrika 88(3):767-778

33. Nylund KL, Asparouhov T, Muthén BO (2007) Deciding on the number of classes in latent class analysis and growth mixture modeling: a Monte Carlo simulation study. Struct Equ Modeling 14(4):535-569. https://doi.org/10.1080/10705510701575396

34. Storey DJ, Waters RA, Hibberd CJ, Rush RW, Cargill AT, Wall LR et al (2007) Clinically relevant fatigue in cancer outpatients: the Edinburgh Cancer Centre symptom study. Ann Oncol 18(11):1861-1869. https://doi.org/10.1093/annonc/mdm349

35. Stone P, Richardson A, Ream E, Smith AG, Kerr DJ, Kearney N (2000) Cancer-related fatigue: inevitable, unimportant and untreatable? Results of a multi-centre patient survey. Cancer Fatigue Forum Ann Oncol 11(8):971-975. https://doi.org/10. 1023/a:1008318932641

36. Brown DJ, McMillan DC, Milroy R (2005) The correlation between fatigue, physical function, the systemic inflammatory response, and psychological distress in patients with advanced lung cancer. Cancer 103(2):377-382. https://doi.org/10.1002/cncr. 20777

37. Simmonds MJ (2002) Physical function in patients with cancer: psychometric characteristics and clinical usefulness of a physical performance test battery. J Pain Symptom Manage 24(4):404-414. https://doi.org/10.1016/s0885-3924(02)00502-x

38. Wen CP, Wai JPM, Tsai MK, Yang YC, Cheng TYD, Lee M-C et al (2011) Minimum amount of physical activity for reduced mortality and extended life expectancy: a prospective cohort study. Lancet 378(9798):1244-1253. https://doi.org/10.1016/ S0140-6736(11)60749-6

39. Brown JC, Winters-Stone K, Lee A, Schmitz KH (2012) Cancer, physical activity, and exercise. Compr Physiol 2(4):2775-2809. https://doi.org/10.1002/cphy.c120005

40. Douglas E (2005) Exercise in cancer patients. Phys Ther Rev 10(2):71-88. https://doi.org/10.1179/108331905X43490

41. Mishra SI, Scherer RW, Snyder C, Geigle PM, Berlanstein DR, Topaloglu O (2012) Exercise interventions on health-related quality of life for people with cancer during active treatment. Cochrane Database Syst Rev 2012(8):Cd008465. https://doi.org/10.1002/ 14651858.CD008465.pub2

42. Lis CG, Gupta D, Lammersfeld CA, Markman M, Vashi PG (2012) Role of nutritional status in predicting quality of life outcomes in cancer-a systematic review of the epidemiological literature. Nutr J 11:27. https://doi.org/10.1186/1475-2891-11-27

43. Marín Caro MM, Laviano A, Pichard C (2007) Nutritional intervention and quality of life in adult oncology patients. Clin Nutr 26(3):289-301. https://doi.org/10.1016/j.clnu.2007.01.005

44. Bower JE (2008) Behavioral symptoms in patients with breast cancer and survivors. J Clin Oncol 26(5):768-777. https://doi. org/10.1200/JCO.2007.14.3248

45. Bubis LD, Davis L, Mahar A, Barbera L, Li Q, Moody L et al (2018) Symptom burden in the first year after cancer diagnosis: an analysis of patient-reported outcomes. J Clin Oncol 36(11):11031111. https://doi.org/10.1200/jco.2017.76.0876

46. Barbera L, Seow H, Howell D, Sutradhar R, Earle C, Liu Y et al (2010) Symptom burden and performance status in a population-based cohort of ambulatory cancer patients. Cancer 116(24):5767-5776. https://doi.org/10.1002/cncr.25681

47. Prigozin A, Uziely B, Musgrave CF (2010) The relationship between symptom severity and symptom interference, education, age, marital status, and type of chemotherapy treatment in Israeli women with early-stage breast cancer. Oncol Nurs Forum 37(6):E411-E418. https://doi.org/10.1188/10.Onf.E411-e418

48. Yancik R, Wesley MN, Ries LA, Havlik RJ, Edwards BK, Yates JW (2001) Effect of age and comorbidity in postmenopausal breast cancer patients aged 55 years and older. JAMA 285(7):885-892. https://doi.org/10.1001/jama.285.7.885 
49. Hensel M, Egerer G, Schneeweiss A, Goldschmidt H, Ho AD (2002) Quality of life and rehabilitation in social and professional life after autologous stem cell transplantation. Ann Oncol 13(2):209-217. https://doi.org/10.1093/annonc/mdf031

50. Abdelsattar ZM, Wong SL, Regenbogen SE, Jomaa DM, Hardiman KM, Hendren S (2016) Colorectal cancer outcomes and treatment patterns in patients too young for average-risk screening. Cancer 122(6):929-934. https://doi.org/10.1002/cncr.29716

51. Cheung WY, Le LW, Gagliese L, Zimmermann C (2011) Age and gender differences in symptom intensity and symptom clusters among patients with metastatic cancer. Support Care Cancer 19(3):417-423. https://doi.org/10.1007/s00520-010-0865-2

52. Cleeland CS, Zhao F, Chang VT, Sloan JA, O'Mara AM, Gilman PB et al (2013) The symptom burden of cancer: evidence for a core set of cancer-related and treatment-related symptoms from the Eastern Cooperative Oncology Group Symptom Outcomes and Practice Patterns study. Cancer 119(24):4333-4340. https:// doi.org/10.1002/cncr.28376

53. Kenzik KM, Martin MY, Fouad MN, Pisu M (2015) Healthrelated quality of life in lung cancer survivors: latent class and latent transition analysis. Cancer 121(9):1520-1528. https://doi. org/10.1002/cncr.29232

Publisher's Note Springer Nature remains neutral with regard to jurisdictional claims in published maps and institutional affiliations. 